\title{
SHORT TERM EFFECT OF LAPAROSCOPIC SLEEVE GASTRECTOMY ON TYPE 2 DIABETIC MORBID OBESE PATIENTS
}

\author{
By
Mohamed Abd El-Bary Abd El-Latif, Mohamed Ahmed Saeed, Ashraf Abd El-Meneam Sayed and Al-Sayed Basiony Moghazy \\ General Surgery and Clinical Pathology Departments, Faculty of Medicine, Al-Azhar \\ University, Egypt \\ Corresponding author: Mohamed Abd El-Bary Abd El-Latif, \\ Mobile: +20116243519, E-mail: mohamedsafouh59@gmail.com
}

\begin{abstract}
Background: Obesity is a medical condition in which excess body fat has accumulated to extend that it may has an adverse effect on health. Leading to reduction of life expectancy or increasing health problems.

Objective: To evaluate the improvement in plasma glucose level and lipid profile in type 2 diabetes mellitus obese patients after Laparoscopic Sleeve Gastrectomy (LSG).

Patients and methods: This prospective study was conducted at Surgery Department, Al-Azhar University Hospitals during the period between December 2019 and August 2020. Study included 30 cases of type 2 diabetes mellitus morbidly obese patients (with BMI $\geq 35 \mathrm{Kg} / \mathrm{m}^{2}$ ) and all of them had failed in trials of conservative management including dietary control, and they were bulky eater but non sweet eater. Laparoscopic sleeve gastrectomy technique was done for all cases.

Results: Our result showed that there was a significant improvement of the HbA1c measured at three and six months post-operatively. Five patients (17\%) completely cured from T2DM, while 12 patients (40\%) became pre-diabetic, and 13 patients (43\%) remained diabetic with great improvement of their previous follow up of HbAlc.
\end{abstract}

Conclusion: LSG was efficient in the remission and/or improvement of symptoms of T2DM and other obesity-related comorbidities, with a significant reduction in serum $\mathrm{HbA1c}$ and lipid profile.

Keywords: Laparoscopic Sleeve Gastrectomy, Type 2 Diabetes mellitus, Morbid Obese.

\section{INTRODUCTION}

Obesity is a medical condition in which excess body fat has accumulated to extend that it may has an adverse effect on health. Leading to reduction of life expectancy or increasing health problems (Allison et al., 2016).

The prevalence of morbid obesity rapidly increasing Worldwide. As surgery has been recognized to be the only long- term treatment for morbid obesity. However surgical therapy can be associated with complications (Msika and Castel, 2014).

Bariatric surgery is the only modality that provides significant sustained weight loss in morbidly obese patients, with improvement of associated comorbidities (Sjostrom et al., 2012). 
Laparoscopic sleeve gastrectomy (LSG) is emerging as a new promising therapy for the treatment of morbid obesity. This procedure, originally conceived as a first stage for achieving weight loss in super-obese patients before performing gastric bypass or biliopancreatic diversion (GBP or BPD), has revealed to be effective on its own and a potential competitor with these operations. In fact, LSG has the advantage to be less invasive than GBP and BDP, and not inferior in terms of sustained weight loss, as demonstrated in some preliminary studies (Baltasar et al., 2015).

The SG produces weight loss by two mechanisms: Firstly, it produces early satiety as a purely restrictive procedure; secondly, it reduces plasma ghrelin levels (Langer et al., 2015).

We aimed in this study to evaluate the improvement in plasma glucose level and lipid profile in type 2 diabetes mellitus obese patients after Laparoscopic Sleeve Gastrectomy (LSG).

\section{PATIENTS AND METHODS}

This prospective study was conducted at Surgery Department, Al-Azhar University Hospitals during the period between December, 2019 and August, 2020. Study included 30 cases of type 2 diabetes mellitus morbidly obese patients (with $\mathrm{BMI} \geq 35 \mathrm{Kg} / \mathrm{m}^{2}$ ), and all of them had failed in trials of conservative management including dietary control, and they were bulky eater but non sweet eater. Laparoscopic sleeve gastrectomy technique was done for all cases.

\section{Inclusion criteria:}

1. Type 2 diabetes mellitus obese patients.

2. $\quad \mathrm{BMI} \geq 35$.

3. Glycated hemoglobin (HbA1c) $6.5 \%$.

4. Type 2 diabetes mellitus patient receiving either oral normoglycemic drugs or insulin.

5. Six months follow up after laparoscopic sleeve gastrectomy with assessment at 0, 3, 6 months interval.

6. Duration of Diabetes Mellitus type 2 more than 2 years.

7. Age between $18-60$ years.

8. No endocrinal causes for obesity.

9. Psychologically stable patients.

10. Motivation\& acceptance of surgical risks.

\section{Exclusion criteria:}

1. Type 1 diabetes mellitus patients.

2. Glycated hemoglobin (HbA1c) < $6.5 \%$.

3. Follow up less than 6 months after sleeve gastrectomy.

4. Post-operative complications.

5. Previous bariatric operations.

\section{Methods:}

All patients were subjected to full history, clinical examination and laboratory investigations (fasting blood sugar on day of operation, HbAlc and lipid profile).

\section{Operative technique:}

A nasogastric tube was inserted at the beginning to decompress the stomach. A 
window was dissected at the junction of the greater curvature and the greater omentum, about $10 \mathrm{~cm}$ from the pylorus. Division of the gastroepiploic, short gastric and posterior fundic vessels was done starting at $4 \mathrm{~cm}$ proximal to the pyloric ring all the way till the angle of His, using the ultracision Harmonic scalpel, (Harmonic; Ethicon Endosurgery, Cincinnati, OH, USA).

Once the dissection part was over, a 36 Fr bougie was introduced orally through the esophagus and inside the stomach. The surgeon then guided it along the lesser curvature and into the pyloric channel and duodenal bulb.

Gastric transection began 4 to $6 \mathrm{~cm}$ proximal to the pylorus. A $60-\mathrm{mm}$, green or gold cartilage was placed across the antrum through the right midepigastric port and fired. The second stapler was placed approximately 1 to $2 \mathrm{~cm}$ from the border of the lesser curvature in the direction of the gastro esophageal junction. The bougie was held in position during this part of the procedure until completion of the stomach transection to avoid stapling across a displaced bougie.

Sequential firings of the stapler along the border of the bougie on the lesser curvature completed the gastric transection at the left crus. After completing the transaction, the entire staple line was inspected carefully to make sure that the staples were well formed especially at the antrum where the stomach was thickest. A layer Vicryl 3/0 was taken either continuous or interrupted at the junction's staples line.

The transected part of the stomach was then removed through one of the $12 \mathrm{~mm}$ port sites. After completion of the gastric transection, the integrity of the staple line was tested by injection of methylene blue through bougie gradually, and under pressure with the pylorus compressed by a surgical grasper. Methylene blue was injected (via the bougie) into the stomach, and the staple line was inspected carefully to exclude macroscopic leaks of the suture line. The dye was then removed from the stomach, as was the bougie. A $18 \mathrm{Fr}$ nelaton drain was inserted along the suture line. All trocar sites were closed with 0 Vicryl (Ethicon) using a suture passer to prevent abdominal wall hernias.

\section{Postoperative follow up:}

In the postoperative period, all patients were given 3rd generation cephalosporins, anticoagulants (discontinued once the patient becomes ambulant), opioids, proton pump inhibitors and antiemetics. Gastrographin meal was done to all patients in day 0 . In day one, all patients started oral fluids (if tolerated) after confirming that there was no leakage in the study. All patients were discharged 24-48 $\mathrm{h}$ postoperatively after meeting the discharge criteria of no bleeding, no leakage and no other complications.

\section{Ethical committee approval:}

The study was approved by the Ethics Board of Al-Azhar University and an informed written consent was taken from each participant in the study.

\section{Statistical Analysis:}

The collected data were coded, processed and analyzed using the SPSS (Statistical Package for the Social Sciences) version 21 for Windows ${ }^{\circledR}$ (SPSS Inc, Chicago, IL, USA). Comparison between groups was done by Chi-Square test for qualitative data. 
Quantitative data was presented as mean \pm SD and range. Qualitative data was presented as number and percent. ANOVA test was used to compare between more than two groups. $\mathrm{P}<0.05$ was considered to be statistically significant.

\section{RESULTS}

This study included 30 patients, their mean of age was (33.6) years and $(78 \%)$ of patients were women while $(22 \%)$ were men. Minimum weight was $101 \mathrm{kgs}$ and maximum weight was $166 \mathrm{kgs}$ with mean of $137.8 \mathrm{~kg}$.

There is significant improvement of the HbAlc measured at three and six months post-operative. Five patients (17\%) completely cured from T2DM while 12 patients $(40 \%)$ became pre-diabetic and 13 patients $(43 \%)$ remain diabetic with great improvement of their previous follow up of HbA1c (Table 1).

Table (1): Glycated hemoglobin at 6 months follow up

\begin{tabular}{|c|c|c|}
\hline Reference range & No. of patients & \% of the patient \\
\hline HbA1C <5.7\% (Non-diabetic) & 5 & $17 \%$ \\
\hline HbA1C (5.7-6.4\%) (Pre-diabetic) & 12 & $40 \%$ \\
\hline HbA1C ( $\geq \mathbf{6 . 5 \% )}$ (Diabetic) & 13 & $43 \%$ \\
\hline
\end{tabular}

For total cholesterol we observed a statistically significant decrease of its level 3 and 6 months postoperative, average total cholesterol preoperative was 186.71, average total cholesterol 3 month postoperative was161.51and average total cholesterol 6 months postoperative was 149.65, p value (0.002) indicating significant decrease postoperative.

During the examination of TG concentration, we stated a statistically significant decrease of its value after 3,6 months in comparison to preoperative value, average triglycerides preoperative was 127.71, average triglycerides 3 month postoperative was 111.14 and average triglycerides 6 month postoperative was 101.15 , p value (0.004) showed significant decrease.
During the examination of LDL level pre and postoperative, we stated a statistically significant decrease of its value after 3,6 months in comparison to preoperative value, average LDL preoperative was 116.12 , average LDL 3 month postoperative was 107.41 and average LDL 6 month postoperative was 101.21, p value (0.026) showing significant decrease postoperative.

Significant increase was observed after 3, 6 months after the surgery in comparison to preoperative value, average HDL preoperative was 45.15 , average HDL 3 month postoperative was 49, 01 and average HDL 6 month postoperative was 56.12, $\mathrm{p}$ value (0.014) showing significant increase postoperative (Table 2). 
Table (2): Comparison between lipid profile parameters preoperatively and postoperatively

\begin{tabular}{|c|c|c|c|c|c|c|}
\hline \multicolumn{2}{|c|}{ Parameters } & $\begin{array}{l}\text { Pre-op } \\
(\mathbf{n}=\mathbf{3 0})\end{array}$ & $\begin{array}{c}3 \text { months post } \\
\text { op }(n=30)\end{array}$ & $\begin{array}{c}6 \text { months post } \\
\text { op }(n=30)\end{array}$ & $\mathbf{F}$ & p-value \\
\hline \multirow{2}{*}{$\begin{array}{c}\text { Total } \\
\text { cholesterol }\end{array}$} & Mean & 186.71 & 161.51 & 149.65 & \multirow{2}{*}{10.4} & \multirow{2}{*}{$<0.001$} \\
\hline & $\pm \mathrm{SD}$ & 29.24 & 31.96 & 34.92 & & \\
\hline \multirow{2}{*}{ Triglyceride } & Mean & 127.71 & 111.14 & 101.15 & \multirow{2}{*}{4.24} & \multirow{2}{*}{0.017} \\
\hline & \pm SD & 29.24 & 35.32 & 41.43 & & \\
\hline \multirow{2}{*}{ LDL } & Mean & 116.12 & 107.41 & 101.21 & \multirow{2}{*}{1.55} & \multirow{2}{*}{0.217} \\
\hline & \pm SD & 35.97 & 31.97 & 30.47 & & \\
\hline \multirow{2}{*}{ HDL } & Mean & 45.15 & 49.01 & 56.12 & \multirow{2}{*}{5.51} & \multirow{2}{*}{0.006} \\
\hline & \pm SD & 6.14 & 12.19 & 17.86 & & \\
\hline
\end{tabular}

\section{DISCUSSION}

Laparoscopic sleeve gastrectomy is categorized as a restrictive bariatric procedure; however, LSG is also a metabolic procedure due to the changes in gut hormones induced by the operation in addition to the caloric restriction effect thus leading to an important role in the field of bariatric surgery (Iannelli et al., 2019).

In this study, we operated on 30 morbid obese patients with body mass index 35 or more then follow up of HbA1c and lipid profile diameters was done at day of operation and then follow up at three and six months after surgery. The study showed a great improvement of the glycaemia control of most of the patient also showed a marked regression of $\mathrm{HbA} 1 \mathrm{c}$ level with $17 \%$ completely cured from T2DM while $40 \%$ became prediabetic and $43 \%$ remain diabetic with great improvement of their previous follow up of HbA1c. And there is resolved or improved lipid profile in a majority of patients. 6 months after surgery significant change in lipid profile include serum HDL cholesterol level with decreased level of TG and LDL level.
Also, there were no postoperative complications, morbidity or mortality had occurred in any patient included in our study.

In comparison to other studies done by Guo et al. (2017), twenty-four obese patients with T2DM and BMI less than 40 $\mathrm{kg} / \mathrm{m} 2$ received LSG. The study showed the overall remission rate of diabetes.

Similar results were obtained by team of Strain et al. (2011), as in our study. Feng et al., also indicated that low level of HDL cholesterol and high TG, LDL are the main risk factor for cardiovascular disease in obese patient. Regarding the cardiovascular risk the observed increased HDL and decrease TG, LDL level is fairly positive prognostic factor.

Wadden et al. (2011) has proved That LSG highly effective in alleviating type 2 diabetes and its complications compared with traditional medical treatment.

Leonetti et al. (2012) stated that mean body mass index increased, but all patients remained diabetic.

In another retrospective study that compared obese subjects undergoing bariatric surgery with obese patients allocated to a matched, conventionally 
treated control group with an average follow-up of 12 months. The author of that study concludes that surgery has dramatic positive effects on most cardiovascular risk factors, an excellent effect on established type 2 diabetes, and prevents the development of new cases of this disease. Finally, bariatric surgery was associated with a significant reduction of mortality (Sjöström et al., 2017).

In patients with a T2DM duration of less than 10 years, the remission rate was $100 \%$, as we already reported in another paper concluding that diabetes duration is an important prognostic factor for diabetes remission and/or improvement. Therefore, comparing surgical with medical treatment in patients with more than 10 years of diabetes duration, we found that the effect of LSG is significantly more effective with regard to reducing fasting plasma glucose and HbA1c levels. In those patients, although LSG was effective against diabetes in $40 \%$ of cases, it also allows for better metabolic control when medical therapy is unsuccessful. Moreover, the reductions in the levels of HbA1c and fasting plasma glucose in the medically treated group were obtained during the follow-up period. In the surgical group, however, medication use decreased significantly within the third month (Basso et al., 2011).

\section{CONCLUSION}

This study confirmed the efficacy of LSG in the remission and/or improvement of symptoms of T2DM and other obesityrelated comorbidities with a significant reduction in serum $\mathrm{HbAlc}$ and lipid profile parameters. LSG might play an important role as a metabolic therapy for patients with type $2 \mathrm{DM}$.
Conflicts of interest: No conflicts of interest were encountered.

\section{REFERENCES}

1. Allison DB and Saunders L (2016): Obesity in North America. Med Clin North Am., 84(2): 305-32.

\section{Baltasar A, Serra $C$ and Perez N.} (2015): Laparoscopic sleeve gastrectomy: a multi-purpose bariatric operation. Obes Surg., 15: 1124-1128.

\section{Basso N, Casella $G$ and Rizzello $M$} (2011): Laparoscopic sleeve gastrectomy as first stage or definitive intent in 300 consecutive cases. Surg Endosc., 25:444-449.

4. Guo, Y., Du, H., Chen, Y., Bragg, F. and Holmes, A. (2017): Association between diabetes and cause -specific mortality in rural and urban areas of china. JAMA, 317(3): 280-289.

5. Iannelli, A., Treacy, P., Sebastianelli, L., Schiavo, L., and Martini, F. (2019): Perioperative complications of sleeve gastrectomy: Review of the literature. Journal of Minimal Access Surgery, 15(1): 1-7.

6. Langer FB, Reza Hoda MA, Bohdjalian A, Felberbauer FX, Zacherl J and Wenzl E. (2015): Sleeve gastrectomy and gastric banding: effects on plasma ghrelin levels. Obes Surg., 15: 1024-1029.

7. Leonetti, F., Capoccia, D., Coccia, F., Casella, G., Baglio, G. and Paradiso, F. (2012): Obesity, type 2 diabetes mellitus, and other comorbidities: a prospective cohort study of laparoscopic sleeve gastrectomy vs medical treatment. Archives of Surgery, 147(8): 694-700. 
8. Msika S and Castel B. (2014): Present indications for surgical treatment of morbid obesity: how to choose the best operation? J Visc Surg., 147: e47-e51.

9. Sjostrom L, Lindroos AK and Peltonen M. (2012): Lifestyle, diabetes, and cardiovascular risk factors 10 years after bariatric surgery. N Engl J Med., 351(26):2683-2693.

10. Sjöström L, Narbro $K$ and Sjostrum D. (2017): Effects of bariatric surgery on mortality in
Swedish obese subjects. N Engl J Med., 357:741-752.

11. Strainet $\mathbf{G W}$, Zhang $\mathbf{F}$ and Lei W. (2011): Changes in lipid profiles in morbidly obese patients after laparoscopic sleeve gastrectomy (LSG). Obes Surg., 21:305-309.

12. Wadden TA, Berkowitz RL and Sarwer DB. (2011): Benefits of lifestyle modification in the pharmacological treatment of obesity. Arch Intern Med., 161 (2):218-27. 


\section{التأثير قصير الملدى لتكميه المعلة بالمنظار الجراحي على مرضى السمنة

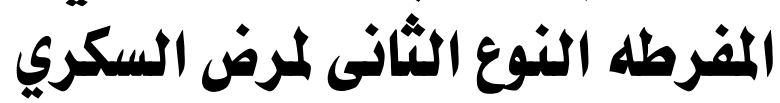

محمد عبد البارى عبد اللطيف, محمد احمد سعيد, أثرف عبد المنعم سيد, السيد بسيونى مغازى

قسمى الجراحة العامة و الباثولوجيا الإكلينيكية, كلية الطب, جامعة الازهر, القاهرة, مصر

المؤلف: محمد عبد البارى عبد اللطيف،

Mobile: +20116243519, E-mail: mohamedsafouh59@gmail.com

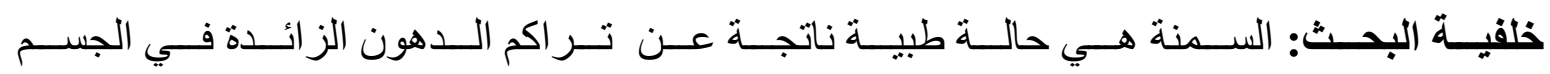

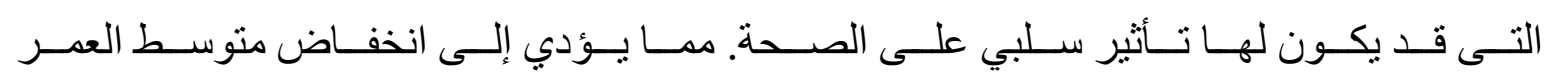
المتوقع أو زيادة المشاكل الصحية.

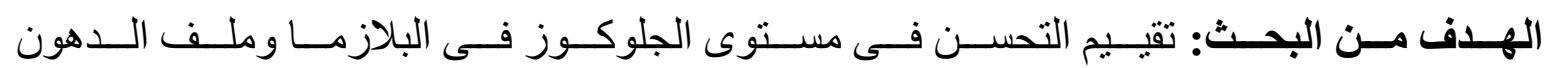

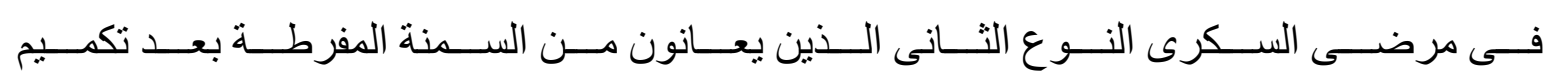
المعدة بالمنظار.

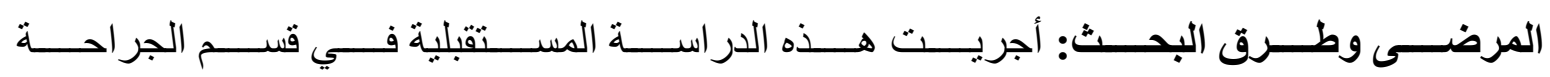

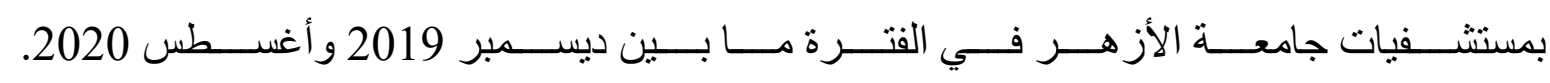

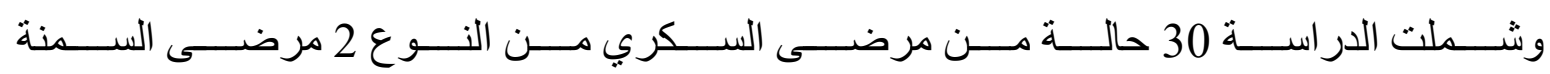

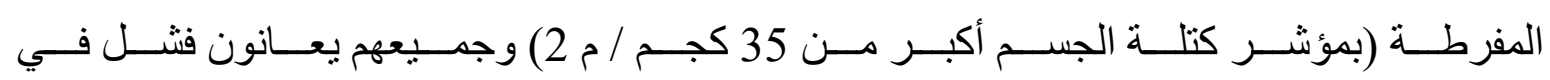

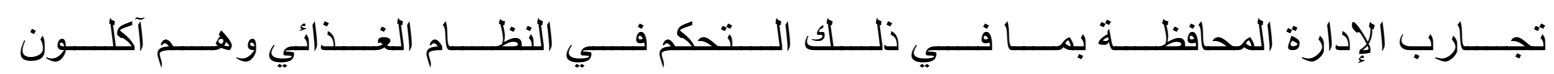
ضخمون لكن ليسو آكلين للحلوى. تتم تقنية تكميم المعدة بالمنظار لجميع الحالات.

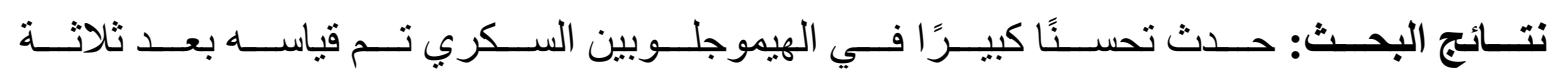

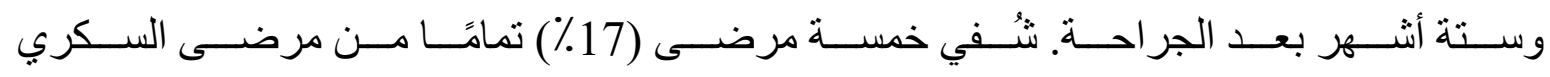

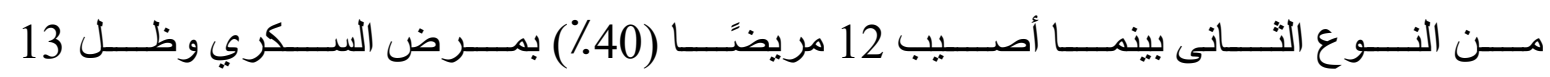

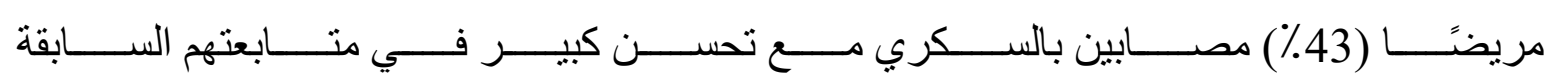

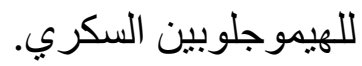




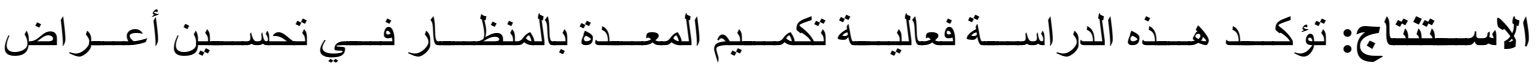

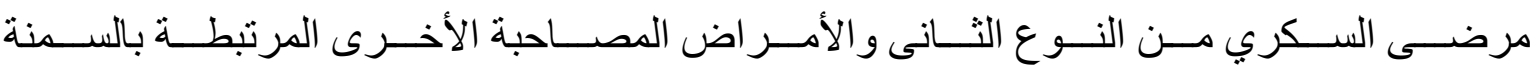
مع انخفاض كبير في نسبة الهيموجلوبين السكري.

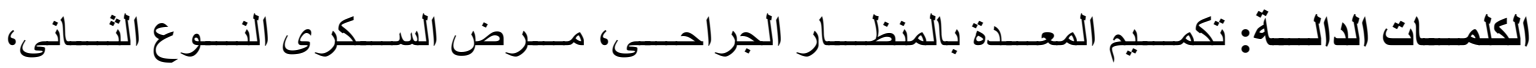
السمنة المفرطة. 